\title{
Evaluating the Comprehensive Performance of 5G Base Station: A Hybrid MCDM Model Based on Bayesian Best-Worst Method and DQ-GRA Technique
}

\author{
Mingliang Liang, ${ }^{1}$ Wenxuan Li, ${ }^{1}$ Jie Ji, ${ }^{1}$ Zhenxi Zhou, ${ }^{2}$ Yihang Zhao $\mathbb{C D}^{2}$ Huiru Zhao, ${ }^{2}$ \\ and Sen Guo ${ }^{2}$ \\ ${ }^{1}$ North China Branch of State Grid Corporation of China, Beijing 100053, China \\ ${ }^{2}$ School of Economics and Management, North China Electric Power University, Beijing 102206, China \\ Correspondence should be addressed to Yihang Zhao; 120202106017@ncepu.edu.cn
}

Received 13 December 2021; Accepted 15 January 2022; Published 31 January 2022

Academic Editor: Chiranjibe Jana

Copyright (c) 2022 Mingliang Liang et al. This is an open access article distributed under the Creative Commons Attribution License, which permits unrestricted use, distribution, and reproduction in any medium, provided the original work is properly cited.

\begin{abstract}
In recent years, $5 \mathrm{G}$ technology has rapidly developed, which is widely used in medical, transportation, energy, and other fields. As the core equipment of the $5 \mathrm{G}$ network, $5 \mathrm{G}$ base stations provide wireless coverage and realize wireless signal transmission between wired communication networks and wireless terminals. However, as the scale of $5 \mathrm{G}$ base stations gradually increases, problems such as poor user experience and insufficient coverage area frequently occur. Hence, it is necessary to evaluate the comprehensive performance of $5 \mathrm{G}$ base stations, so as to clarify the problems existing in the construction of base stations. First, the performance evaluation index system is constructed from the perspectives of operational performance, financial performance, environmental impact, and social influence. Then, a novel hybrid multicriteria decision-making (MCDM) model based on the Bayesian bestworst method (BBWM) and difference-quotient gray relational analysis (DQ-GRA) technique is adopted. Finally, sixteen 5G base stations are taken as examples for analysis. The result shows that the signal coverage area and per capita input cost are the most important indicators greatly affecting the overall performance of the $5 \mathrm{G}$ base station. Compared with the two other MCDM models, the proposed hybrid MCDM model has good applicability and effectiveness for performance evaluation of $5 \mathrm{G}$ base stations.
\end{abstract}

\section{Introduction}

1.1. Background and Motivation. With the rapid development of the mobile internet, people's requirements for the quality and speed of mobile communication are constantly improving. As a new generation of mobile communication technology after 2020, the 5th-generation mobile communication technology $(5 \mathrm{G})$ becomes the future direction of wireless technology development [1]. The 5th-generation mobile communication technology has the characteristics of high speed, low delay, and large connection, which can provide users with faster and better services [2]. At the same time, the emergence and promotion of $5 \mathrm{G}$ have made communication break through the previous fixed mode and opened the curtain of the era of coconnection between man and everything [3].

With the popularization of $5 \mathrm{G}$ technology, the construction of $5 \mathrm{G}$ base stations is also in full swing. On March 24, 2020, the Ministry of Industry and Information Technology of the People's Republic of China issued the "Notice on Accelerating the Development of 5G," which clearly stated that the construction and deployment of $5 \mathrm{G}$ networks should be accelerated. By January 2021, China had built over eight hundred thousand $5 \mathrm{G}$ base stations, ranking first in the world in terms of speed and scale of 5G network construction. According to the data released by local government departments, the scale of $5 \mathrm{G}$ base station construction in 31 provinces (autonomous regions and municipalities) of 
China is listed in Table 1 and the layout of $5 \mathrm{G}$ base stations in various regions is shown in Figure 1.

As can be seen from Figure 1, there is a big gap in the quantity of $5 \mathrm{G}$ base stations across China. Of which, there are nearly 124,000 5G base stations in Guangdong while there are only 1,900 5G base stations in Qinghai. There are obvious regional differences in the distribution of $5 \mathrm{G}$ base stations in China. Overall, the distribution of $5 \mathrm{G}$ base station shows a trend of gradual decrease from east to west.

Meanwhile, with the gradual increase in the number of $5 \mathrm{G}$ base stations, more and more problems continue to be revealed, such as neighbor avoidance effect, ecological environmental impact, and compatibility with the current mobile communication system. Under this background, it is necessary to evaluate the performance of $5 \mathrm{G}$ base stations and judge the effectiveness of $5 \mathrm{G}$ base station construction. Besides, the evaluation of the comprehensive performance of the $5 \mathrm{G}$ base station can provide a certain theoretical basis for the future $5 \mathrm{G}$ base station site selection.

1.2. Literature Review. As a new generation of mobile communication technology, $5 \mathrm{G}$ has received extensive attention from scholars in recent years. The research directions mainly include the following aspects.

1.2.1. 5G Key Technologies. Akyildiz et al. [4] analyzed the current 10 key enabling technologies and studied the challenges and shortcomings of various technologies. According to the type of technology, it can be divided into the following aspects: (1) a wireless software-defined network, (2) network function virtualization, (3) millimeter wave spectrum, (4) massive MIMO, (5) network ultradensification, (6) big data and mobile cloud computing, (7) scalable internet of things, (8) device-to-device connectivity with high mobility, (9) green communications, and (10) new radio access technique.

Table 2 presents the studies on 5G key technologies in recent years and briefly introduces the methods and contributions of these studies.

1.2.2. 5G Application Scenarios. In addition to the exploration of $5 \mathrm{G}$ technologies, scholars are also committed to studying possible future application scenarios of $5 \mathrm{G}$. Table 3 presents the studies on $5 \mathrm{G}$ application scenarios in recent years and briefly introduces the methods and contributions of these studies.

1.2.3. $5 G$ Base Station. As the core equipment of the $5 G$ network, the $5 \mathrm{G}$ base station provides wireless coverage to realize wireless signal transmission between the wired communication network and wireless terminal. In recent years, there have been more research studies on $5 \mathrm{G}$ base stations.

Yan and Ma [15] proposed an efficient and secure handover authentication protocol at neighbor base stations, gNodeBs (gNBs) for secure handovers, which demonstrated ability against various malicious attacks. Wang et al. [16]
TABLE 1: The $5 \mathrm{G}$ base station construction scale in various regions of China.

\begin{tabular}{|c|c|c|}
\hline Region & $\begin{array}{l}5 \mathrm{G} \text { base station } \\
\text { construction scale }\end{array}$ & Expiration date \\
\hline Guangdong & 124,000 & Nov. 2020 \\
\hline Jiangsu & 71,000 & Nov. 2020 \\
\hline Zhejiang & 62,600 & Oct. 2020 \\
\hline Shandong & 51,000 & Dec. 2020 \\
\hline Chongqing & 49,000 & Oct. 2020 \\
\hline Henan & 45,400 & Dec. 2020 \\
\hline Sichuan & 39,000 & Jan. 2021 \\
\hline Beijing & 37,000 & Dec. 2020 \\
\hline Jiangxi & 31,000 & Nov. 2020 \\
\hline Shanghai & 30,000 & Planning \\
\hline Hunan & 29,000 & Dec. 2020 \\
\hline Hubei & 26,100 & Dec. 2020 \\
\hline Tianjin & 24,000 & Dec. 2020 \\
\hline Fujian & 22,500 & Dec. 2020 \\
\hline Anhui & 21,400 & Aug. 2020 \\
\hline Guangxi & 21,000 & Dec. 2020 \\
\hline Hebei & 21,000 & Dec. 2020 \\
\hline Liaoning & 20,000 & Sept. 2020 \\
\hline Guizhou & 20,000 & Dec. 2020 \\
\hline Heilongjiang & 19,800 & Dec. 2020 \\
\hline Yunnan & 18,500 & Dec. 2020 \\
\hline Shanxi & 18,000 & Dec. 2020 \\
\hline Shaanxi & 18,000 & Dec. 2020 \\
\hline Gansu & 8100 & Nov. 2020 \\
\hline Jilin & 8000 & Dec. 2020 \\
\hline Xinjiang & 5300 & Oct. 2020 \\
\hline Inner Mongolia & 4500 & Oct. 2020 \\
\hline Ningxia & 4000 & Planning \\
\hline Tibet & 3600 & Dec. 2020 \\
\hline Hainan & 2100 & Nov. 2020 \\
\hline Qinghai & 1900 & Aug. 2020 \\
\hline Total & 857,000 & - \\
\hline
\end{tabular}

conducted in-depth research on the location of $5 \mathrm{G}$ base stations based on geographic information system (GIS) and heuristic optimization algorithms, which can provide reasonable and robust results to support 5G cellular network planning. Sigwele et al. [17] proposed a dynamic pico BS switching OFF algorithm based on a utility function. The proposed scheme maintains coverage and quality of service (QoS) and can effectively save more than $40 \%$ of energy consumption. Qian et al. [18] proposed a centralized radio access network architecture as a possible solution for an energy-efficient fifth-generation (5G) mobile system. The architecture effectively solved the problem that different types of radio resources and hardware resources cannot be shared and allocated within the overall network in a cooperative way.

According to the existing literature, several conclusions can be drawn.

(1) The existing research on 5G mainly revolves around three parts: technology, application scenarios, and base stations. Relying on key technologies such as network function virtualization, massive MIMO, and wireless software-defined network, $5 \mathrm{G}$ has been 


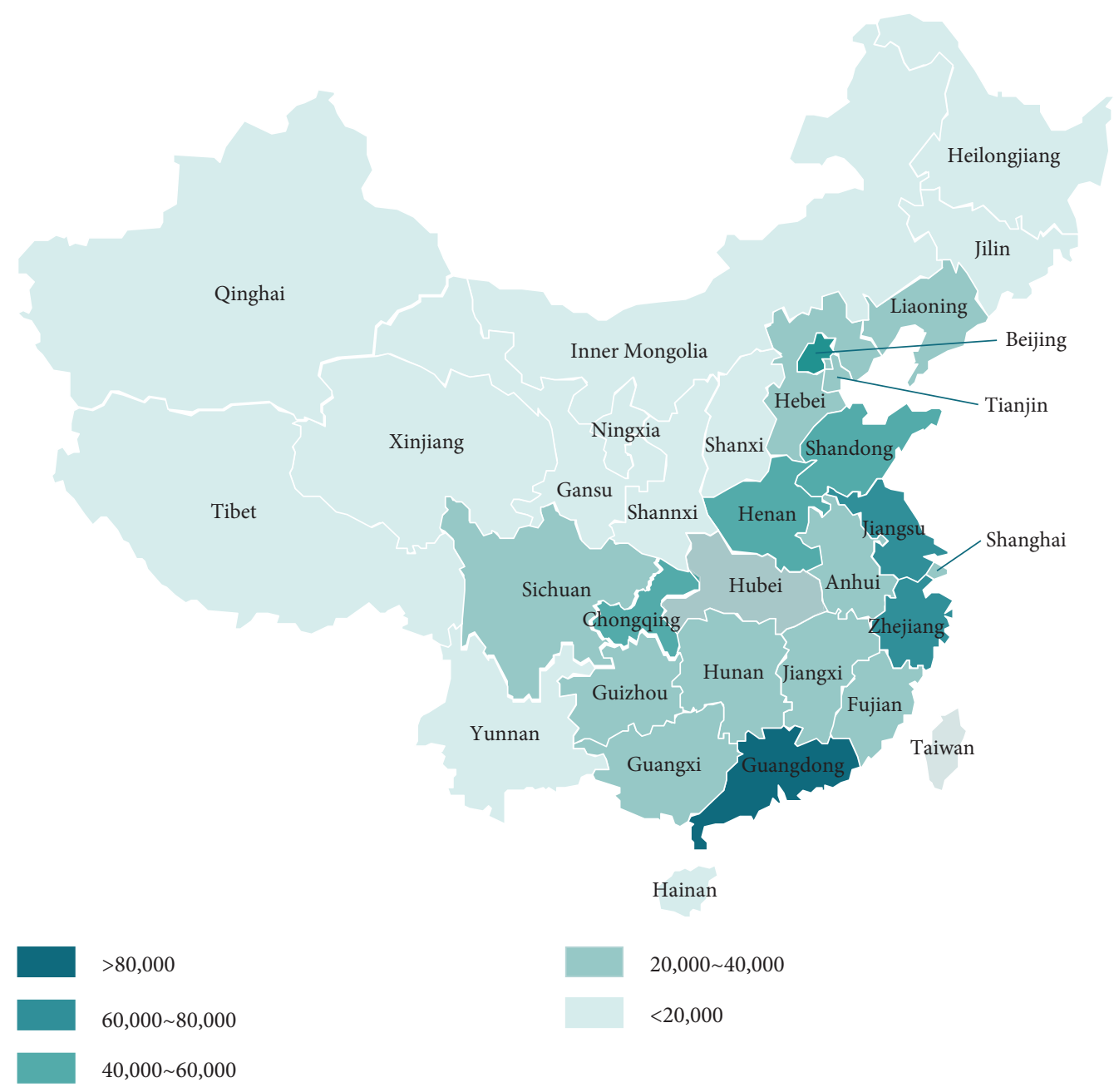

FIgUre 1: The layout of $5 \mathrm{G}$ base stations in various regions of China.

TABLE 2: The studies on 5G key technologies in recent years.

\begin{tabular}{|c|c|c|}
\hline Reference & Key technology & Contribution \\
\hline Charles et al. [5] & $\begin{array}{l}\text { 5G wireless sensor } \\
\text { networks }\end{array}$ & This study proposed solutions available to identify and avoid cyber threats \\
\hline Xie et al. [6] & $\begin{array}{l}\text { Network function } \\
\text { virtualization }\end{array}$ & $\begin{array}{l}\text { This study proposed a WEB-MACRO method to solve the problems of service migration } \\
\text { and fluctuation for queues in the networks }\end{array}$ \\
\hline $\begin{array}{l}\text { Juneja and } \\
\text { Sharma [7] }\end{array}$ & Millimeter wave spectrum & $\begin{array}{c}\text { This study presented propagation-related issues of mmW frequencies and modeling- } \\
\text { related issues in CMOS technology }\end{array}$ \\
\hline Wen & Massive MIMO & $\begin{array}{l}\text { This study developed refined channel estimation routines and localization methods to } \\
\text { perform massive MIMO localization }\end{array}$ \\
\hline $\begin{array}{l}\text { Sharma and } \\
\text { Kumar [9] }\end{array}$ & $\begin{array}{c}\text { Network } \\
\text { ultradensification }\end{array}$ & $\begin{array}{l}\text { This study provided a detailed survey of resource allocation approaches for UDNs in 5G } \\
\text { and beyond networks }\end{array}$ \\
\hline
\end{tabular}

widely researched and applied in $\mathrm{VR}$ video, cloud computing, smart city, and other fields.

(2) The research on $5 \mathrm{G}$ base stations is mainly about energy saving and consumption reduction in base stations. There are relatively few studies evaluating the performance of $5 \mathrm{G}$ base stations.

In fact, there has been a lot of research on the performance evaluation of underground subway stations [19], petrol station [20], grid-tied photovoltaic station [21], and other aspects, which can provide a reference for the comprehensive performance evaluation of $5 \mathrm{G}$ base stations in this study.

1.3. Contributions and Article Organization. Based on the previous research, this study proposes a hybrid multicriteria decision-making (MCDM) model to evaluate the comprehensive performance of the $5 \mathrm{G}$ base station. First, the evaluation index system is conducted from the perspective of 
operational performance, financial performance, environmental impact, and social influence. Then, the Bayesian bestworst method (BBWM) is applied to determine the weights of criteria. Finally, the difference-quotient gray relational analysis (DQ-GRA) model is proposed to evaluate the comprehensive performance of the base stations. The main contributions and innovations of this study are as follows:

(1) In recent years, the number of $5 G$ base stations has rapidly grown, and there have been problems such as overlapped coverage area, low service load access, and poor surrounding user experience. This study studies the comprehensive performance of the $5 \mathrm{G}$ base station with a problem-oriented perspective, which can fill the gaps in existing research.

(2) This study constructs a comprehensive performance evaluation index system of the $5 \mathrm{G}$ base station. The index system not only concentrates on the traditional operational performance but also considers the financial performance, environmental impact, and social influence.

(3) This study proposes a novel hybrid MCDM model for the performance evaluation of $5 \mathrm{G}$ base stations. The index weighting method (BBWM) takes the group decision-making environment into consideration to make the weighting results more realistic. The evaluation model (DQ-GRA) realizes the improvement of traditional GRA, which simultaneously considers the degree of geometric similarity and the degree of numerical proximity.

The other sections of this study are structured as below. Following the introductory section, Section 2 constructs the comprehensive performance evaluation index system of $5 \mathrm{G}$ base station and expounds on the connotation of each indicator. Section 3 mainly introduces the basic theory of the Bayesian best-worst method and the DQ-GRA model. Section 4 carries on the case study, and Section 5 compares the evaluation result with other models. Section 6 presents the conclusions and limitations.

\section{Evaluation Index System for Comprehensive Performance Evaluation of the 5G Base Station}

The evaluation index system is extremely important for the performance evaluation of the $5 \mathrm{G}$ base station. Clear, comprehensive, and specific indicators should be included in the evaluation index system, which can reflect the main characteristics and connotations of the $5 \mathrm{G}$ base station. In this study, the performance evaluation of $5 \mathrm{G}$ base station is analyzed and evaluated with the consideration of different perspectives such as operational, financial, environmental, and social performance. The evaluation index system for comprehensive performance evaluation of $5 \mathrm{G}$ base station is shown in Figure 2.

2.1. Operational Performance. The extensive coverage of $5 \mathrm{G}$ networks can significantly strengthen social governance capabilities. By allowing data to "make suggestions," scientific, refined, and intelligent decision-making schemes can be easily formed. On July 5, 2021, ten Chinese ministries and commissions jointly issued the "5G Application Sailing Action Plan (2021-2023)," which puts forward indicators such as the number of $5 \mathrm{G}$ base stations and the penetration rate of $5 \mathrm{G}$ individual users. This move indicates the determination to improve the supply of $5 \mathrm{G}$ infrastructure for public coverage.

Therefore, the operational performance is essential for evaluating the performance of $5 \mathrm{G}$ base stations. According to the existing literature, signal coverage area and business loadings are selected to be the main indicators for operational performance evaluation.

2.1.1. Signal Coverage Area (C1). Due to the lack of rigorous construction planning, it is prone to overlap the signal coverage of multiple base stations in actual situations [22]. The signal coverage area of the base station cannot be calculated by a simple circular area formula but needs to remove the overlap with other existing base stations. Thus, the signal coverage area of the base station can be calculated by formula (1):

$$
S=\pi r^{2}-\sum_{i} S_{i}
$$

where $S$ represents the signal coverage area of the base station, $r$ represents the signal transmission radius of the base station, and $S_{i}$ represents the overlap area with the $i$-th base station.

$$
P_{r}=P_{t}-32.4-20 \lg (r)-20 \lg (f),
$$

where $P_{r}$ represents the receiving power in free space [23], $P_{t}$ represents the transmit power, and $f$ represents the frequency.

2.1.2. Business Loadings (C2). The main equipment of the $5 \mathrm{G}$ base station mainly includes an active antenna unit (AAU) and baseband unit (BBU) [24]. The energy consumption of the two units accounts for nearly $46 \%$ of the overall energy consumption of the base station, and the energy consumption of AAU equipment mainly depends on the business loadings. The indicator of the annual average load is selected to characterize business loadings.

$$
\bar{L}=\frac{1}{T} \sum_{t=1}^{T} L_{t} t \in[1, T],
$$

where $\bar{L}$ represents the annual average load of the base station, and $L_{t}$ represents the business loadings at time $t$.

2.2. Financial Performance. In addition to the operational performance, financial performance is also essential to the base station. The indicator of per capita input cost can simultaneously take into account the construction cost of the base station and the number of people served. 
TABLE 3: The studies on 5G application scenarios in recent years.

\begin{tabular}{|c|c|c|}
\hline Reference & pplication scenarios & Contribution \\
\hline Liu et al [10] & & tiled scalable VR video caching scheme over $5 \mathrm{G}$ netv \\
\hline [11] & $\mathrm{G}+$ Internet of & 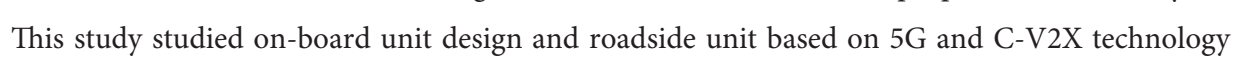 \\
\hline $\begin{array}{l}\text { Yang et al. } \\
{[12]}\end{array}$ & $5 \mathrm{G}+$ wireless & $\begin{array}{r}\text { This study propose } \\
\text { endos }\end{array}$ \\
\hline Jara & $\begin{array}{l}5 \mathrm{G}+\text { energy cloud } \\
\text { system }\end{array}$ & $\begin{array}{l}\text { This study proposed an edge computing-based framework that aims to efficiently manage and } \\
\text { optimize energy cloud systems }\end{array}$ \\
\hline Tan & $5 \mathrm{G}+$ & $\begin{array}{r}\text { This study proposed a blockchain-empowered and decentrali } \\
\text { crowdsourcing system in 5G-enable }\end{array}$ \\
\hline
\end{tabular}

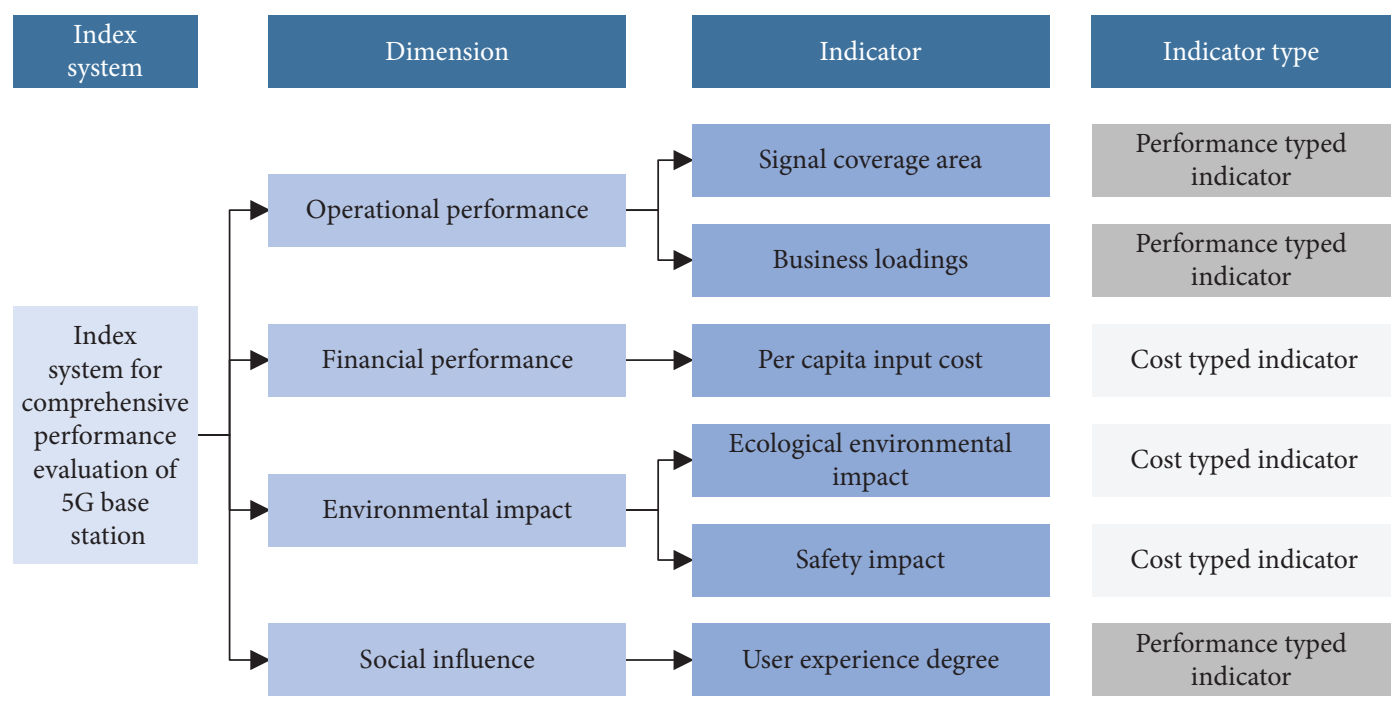

FIGURE 2: The index system for comprehensive performance evaluation of $5 \mathrm{G}$ base station.

\subsubsection{Per Capita Input Cost (C3)}

$$
P C=\frac{C}{P}
$$

where $P C$ represents the per capita input cost of the base station, $C$ represents the investment cost of the base station, and $P$ represents the number of people served by the base station.

2.3. Environmental Impact. In addition to the performance of the base station itself, it is also necessary to consider the impact of the base station on the external environment. In particular, the environmental performance mainly includes two aspects: one is the impact on the ecological environment, and the other one is the impact on safety.

2.3.1. Ecological Environmental Impact (C4). In the construction and operation of $5 \mathrm{G}$ base stations, there may be impacts on the water and soil environment, acoustic environment, and electromagnetic environment. Among them, the monitoring of the electromagnetic radiation environment is most important. The monitoring factor for the electromagnetic radiation environment of $5 \mathrm{G}$ base stations is the radiofrequency electromagnetic field, and the detection parameter is the power density (or electric field strength).

If the unit of the measured value of the electric field intensity read by the monitoring instrument is $d B(\mu \mathrm{V} / \mathrm{m})$, it can be converted into an electric field intensity value in $\mathrm{V} / \mathrm{m}$ according to

$$
E=10^{(x / 20-6)}
$$

where $x$ represents the reading number of the monitoring instrument, and $E$ represents the electric field strength.

The electric field intensity and power density in the far field can be converted according to

$$
S=\frac{E^{2}}{Z_{0}},
$$

where $S$ represents the power density, and $Z_{0}$ represents the free space intrinsic impedance (the value is $120 \pi \Omega$ ).

2.3.2. Safety Impact (C5). The location of the base station should be as far away as possible from the industrial factory. On the one hand, some flammable and explosive materials are easily present in the factory. On the other hand, some harmful gases and dust may be generated during the 
production process of the factory, which will cause certain damage to the surrounding environment.

2.4. Social Influence. The significance of base station construction and operation is to serve customers within its range and provide them with signals. So, it is necessary to evaluate the social influence of base stations from the perspective of user experience degree.

2.4.1. User Experience Degree (C6). User experience is usually affected by many factors. In addition to signal strength and signal quality, it is also related to the user's psychological factors to a certain extent. Although the electromagnetic radiation brought by base stations generally meets national standards, some users still have psychological problems.

For conflicts or misunderstandings of the base station, industry experts, scientific research, and technical personnel can be invited to raise the public's awareness of base stations.

\section{Basic Theory of the Proposed Hybrid MCDM Model for Performance Evaluation of 5G Base Station}

3.1. BBWM for Weight Determination of Evaluation Indicators. BWM is first proposed in 2015 by Rezaei to solve MCDM problems [25], which is much more efficient and convenient than the traditional analytic hierarchy process method. AHP needs $n(n-1) / 2$ pairwise comparisons [26], while BWM only needs $2 n-3$ pairwise comparisons when $n$ decision indicators are taken into consideration. The detailed steps of BWM are elaborated as follows.

Step 1: the evaluation index system is established with $n$ indicators, which can be expressed as $\left\{c_{1}, c_{2}, \ldots, c_{n}\right\}$.

Step 2: the best and worst indicators are determined. Based on the construction of the evaluation index system, the best indicator (the most important indicator) $c_{B}$ and the worst indicator (the least important indicator) $c_{W}$ need to be determined according to the knowledge and experience of the decision-makers.

Step 3: pairwise comparisons between the best indicator $c_{B}$ and all the other indicators in the evaluation index system are conducted. Values 1-9 are used to measure the importance of $c_{B}$ and other indicator, 1 means that $c_{B}$ and $c_{j}$ are equally important, and 9 means that $c_{B}$ is extremely important than $c_{j}$. The "Best-to-Others" vector $A_{B}$ can be expressed as follows:

$$
A_{B}=\left(a_{B 1}, a_{B 2}, \ldots, a_{B n}\right) \text {, }
$$

where $a_{B j}(j=1,2, \ldots n)$ stands for the significance of the best indicator $c_{B}$ to $c_{j}$.

Step 4: pairwise comparisons between the worst indicator $c_{W}$ and all the other indicators in the evaluation index system are conducted. Values 1-9 are used to measure the importance of $c_{W}$ and other indicator, 1 means that $c_{j}$ and $c_{W}$ are equally important, and 9 means that $c_{j}$ is extremely important than $c_{W}$. The pairwise comparisons can obtain the "Others-toWorst" vector $A_{W}$, which is as follows:

$$
A_{W}=\left(a_{1 W}, a_{2 W}, \ldots, a_{n w}\right)
$$

where $a_{j W}(j=1,2, \ldots n)$ stands for the significance of indicator $c_{j}$ to the worst indicator $c_{W}$.

Step 5: the optimal index weights of all the evaluation indicators $\left(\omega_{1}^{*}, \omega_{2}^{*}, \omega_{3}^{*} \ldots \omega_{n}^{*}\right)$ are found. The maximum absolute differences $\left|w_{B} / w_{j}-a_{B j}\right|$ and $\left|w_{j} / w_{W}-a_{j W}\right|$ need to be minimized.

$$
\begin{aligned}
& \operatorname{minmax}_{j}\left\{\left|\frac{w_{B}}{w_{j}}-a_{B j}\right|,\left|\frac{w_{j}}{w_{w}}-a_{j W}\right|\right\}, \\
& \text { s.t. }\left\{\begin{array}{l}
\sum_{j} w_{j}=1, \\
w_{j} \geq 0, j=1,2 \ldots n .
\end{array}\right.
\end{aligned}
$$

The above constraints can be transformed into nonlinear constraint optimization problems, and the optimal weights can be calculated by equation (11).

$$
\text { s.t. }\left\{\begin{array}{l}
\min \xi, \\
\left|\frac{w_{B}}{w_{j}}-a_{B j}\right| \leq \xi, \\
\left|\frac{w_{j}}{w_{W}}-a_{j W}\right| \leq \xi, \\
\sum_{j} w_{j}=1, \\
w_{j} \geq 0, j=1,2 \ldots n .
\end{array}\right.
$$

Step 6: the consistency ratio is calculated. The obtained $\xi$ is represented by $\xi^{*}$, and the consistency ratio $C R(C I$ is a given value) is calculated by $C R=\xi^{*} / C I$. The closer the result is to 0 , the more consistent the evaluation results of the experts are. $C R=0$ means that the expert evaluations are completely consistent.

Although BWM has certain advantages over traditional methods when dealing with MCDM problems, it can only determine the weights of different decision-making indicators according to the subjective judgment of only one decision-maker, which means decision-makers cannot simultaneously determine the weights. If multiple decisionmakers are required to determine the weights, the weights determined by each decision-maker need to average. However, the process of averaging weights has drawbacks such as outlier sensitivity and restricted information provision. This process of determining weights is much more equivalent to multiple mechanical repetitions of a single process, which ignores considering the preferences and judgments of multiple decision-makers at the same time. In 
fact, different decision-makers have different ideas about the best and worst indicators, and only after extending to the group decision-making environment can reliable weights be obtained.

In 2019, a new MCDM method named BBWM was proposed by Mohammadi and Rezaei [27], which can simultaneously weigh different decision-making indicators in the case of multiple decision-makers. On the basis of BWM, BBWM considers the probabilistic interpretations of the inputs and outputs, which means the indicators are seen as random events and the weights are regarded as occurrence likelihoods. Therefore, when determining the input and output, probability distributions with multinomial distribution should be taken into account. The probability mass function for the multinomial distribution related to the worst indicator $A_{W}$ is as follows:

$$
P\left(A_{W} \mid w\right)=\frac{\left(\sum_{j=1}^{n} a_{j W}\right) !}{\prod_{j=1}^{n} a_{j W} !} \prod_{j=1}^{n} w_{j}^{a_{j W}},
$$

where $w$ stands for the probability distribution.

The probability of event $j$ is proportionate to the number of occurrences of the event:

$$
w_{j} \propto \frac{a_{j W}}{\sum_{j=1}^{n} a_{j W}} .
$$

So, the probability of the event for the worst indicator is as follows:

$$
w_{W} \propto \frac{a_{W W}}{\sum_{j=1}^{n} a_{j W}}=\frac{1}{\sum_{j=1}^{n} a_{j W}} .
$$

Equations (7) and (8) are used to obtain the following:

$$
\frac{w_{j}}{w_{W}} \propto a_{j W} .
$$

Similarly, $A_{B}$ can also be modeled by employing multinomial distribution. However, the pairwise comparisons between $A_{B}$ and other indicators and the pairwise comparisons between $A_{W}$ and other indicators are completely opposite:

$$
A_{B} \sim \operatorname{multinomial}\left(\frac{1}{w}\right)
$$

Same as the worst indicator, it can be expressed as follows:

$$
\begin{aligned}
& \frac{1}{w_{j}} \propto \frac{a_{B j}}{\sum_{j=1}^{n} a_{B j}}, \\
& \frac{1}{w_{B}} \propto \frac{a_{B B}}{\sum_{j=1}^{n} a_{B j}}=\frac{1}{\sum_{j=1}^{n} a_{B j}}, \\
& \frac{w_{B}}{w_{j}} \propto a_{B j} .
\end{aligned}
$$

So far, the determination of weights has been transformed into a probability distribution estimate. The Bayesian hierarchical model is used to find the optimal weights.
Suppose there are $K$ decision-makers, the $k^{\text {th }}(k=1,2 \ldots K)$ pairwise comparison vector can be represented as $A_{B}^{k}$ and $A_{W}^{k}$, and the $k^{t h}$ weight can be expressed as $w^{k}$. The overall optimal weight $w^{\text {agg }}$ is computed by the weight of each decision-maker $w^{k}$. In the group decisionmaking of $K$ decision-makers, the joint probability distribution can be obtained as follows:

$$
P\left(w^{a g g}, w^{1: K} \mid A_{B}^{1: K}, A_{W}^{1: K}\right) .
$$

The probability of each individual variable can be computed by

$$
P(x)=\sum_{y} P(x, y),
$$

where $x$ and $y$ represent arbitrary random variables.

Subsequently, the Markov Chain Monte Carlo technique is also used to determine the posterior distribution of BBWM. Interested readers can consult Reference [27], which elaborated the whole process of BBWM.

3.2. DQ-GRA for Comprehensive Performance Evaluation of $5 G$ Base Station. The basic idea of gray relational analysis (GRA) is to determine a data sequence reflecting the characteristics of system behavior and data sequences composed of several factors affecting system behavior, which are, respectively, called reference sequence and comparison sequence [28]. By calculating the degree of association between each comparison sequence and the reference sequence, a comprehensive comparison and ranking of the evaluated objects are made. The detailed steps of GRA are listed as follows.

Step 1: the reference sequence $X_{0}$ and comparison sequence $X_{i}$ are determined.

$$
\begin{aligned}
& X_{0}=\left\{x_{0}(1), x_{0}(2), \ldots, x_{0}(n)\right\}, \\
& X_{i}=\left\{x_{i}(1), x_{i}(2), \ldots, x_{i}(n)\right\},
\end{aligned}
$$

where $x_{0}(j)$ represents the optimal value of the $j$-th indicator.

Step 2 (normalization): for the performance typed indicator, the normalized value is as follows:

$$
x_{i}^{\prime}(j)=\frac{x_{i}(j)-\min x_{i}(j)}{\max x_{i}(j)-\min x_{i}(j)} .
$$

For the cost typed indicator, the normalized value is as follows:

$$
x_{i}^{\prime}(j)=\frac{\max x_{i}(j)-x_{i}(j)}{\max x_{i}(j)-\min x_{i}(j)} .
$$

Step 3: the minimum difference $\Delta_{i \text { min }}$ and maximum difference $\Delta_{i \max }$ are calculated.

$$
\begin{aligned}
\Delta x_{i}(j) & =\left|x_{0}(j)-x_{i}(j)\right|, \\
\Delta_{i \min } & =\min _{i} \min _{j} \Delta x_{i}(j),
\end{aligned}
$$




$$
\Delta_{i \max }=\max _{i} \max _{j} \Delta x_{i}(j)
$$

Step 4: the correlation coefficient between the normalized sequence to be evaluated and the reference sequence is calculated.

$$
\delta_{i}(j)=\frac{\Delta_{i \min }+\rho \Delta_{i \max }}{\Delta x_{i}(j)+\rho \Delta_{i \max }},
$$

where $\delta_{i}(j)$ represents the correlation coefficient, and $\rho$ represents the resolution coefficient. The smaller the $\rho$ means, the greater the resolution. When $\rho \leq 0.5463$, the resolution is the best, usually $\rho=0.5$.

Step 5: the degree of relevance $\gamma_{i}$ is calculated.

$$
\gamma_{i}=\sum_{j=1}^{n} \omega_{j} \delta_{i}(j)
$$

where $\omega_{j}$ represents the weight of the $j$-th indicator, which is calculated by BBWM introduced above.

But there is a problem with traditional GRA. When $x_{i}(1) / x_{0}(1)=x_{i}(2) / x_{0}(2)=\ldots=x_{i}(n) / x_{0}(n)$, $\quad$ theoretically, the degree of relevance between the evaluated sequence and the reference sequence should be 1 , but in fact, it is not. In other words, the traditional GRA only considers the degree of geometric similarity between data sequences but ignores the degree of numerical proximity [29]. Xue et al. [30] proposed a difference-quotient GRA (DQ-GRA) approach, which considered the difference method and the division method to simultaneously define a comprehensive gray relation degree from geometric similarity and numerical proximity. The improvement of the DQ-GRA approach is as follows:

The gray relation degree of geometric similarity $\gamma_{1 j}\left(x_{0}(j), x_{i}(j)\right)$ and the gray relation degree of numerical proximity $\gamma_{2 j}\left(x_{0}(j), x_{i}(j)\right)$ are calculated.

$$
\begin{aligned}
& \gamma_{1 j}\left(x_{0}(j), x_{i}(j)\right)=\frac{1}{e^{\Delta x_{i}(j)}}, \\
& \gamma_{2 j}\left(x_{0}(j), x_{i}(j)\right)=\frac{1}{e^{\left|1-x_{i}^{\prime}(j)\right|}} .
\end{aligned}
$$

The gray relation degree of geometric similarity and numerical proximity is calculated.

$$
\gamma_{i}^{\prime}=\sum_{j=1}^{n} \omega_{j} \sqrt{\gamma_{1 j}\left(x_{0}(j), x_{i}(j)\right) \times \gamma_{2 j}\left(x_{0}(j), x_{i}(j)\right)} .
$$

3.3. Applicability and Superiority of the Proposed Model. The proposed model for evaluating the comprehensive performance of the $5 \mathrm{G}$ base station is composed of BBWM and DQ-GRA. The applicability and superiority of the proposed hybrid model are mainly reflected.

3.3.1. Applicability and Advantages of the Index Weighting Method. Generally, index weighting methods include subjective index weighting methods, objective index weighting methods, and subjective-objective index weighting methods. Common objective index weighting methods mainly include the following: entropy method [31], principal component analysis (PCA) approach [32], and variation coefficient method [33]. The objective index weighting method is characterized by the ability to assign weights to quantitative indicators. Its advantage lies in avoiding the influence of subjective factors, but the disadvantages are as follows: (1) it has higher requirements for data, and (2) it cannot give weights to qualitative indicators. In this study, there are some qualitative indicators (such as user experience) in the comprehensive performance evaluation index system of $5 \mathrm{G}$ base stations. Hence, the traditional objective index weighting method cannot be applied in this study.

BWM is a typical subjective index weighting method with the characteristics of convenience and promptness. But the shortcoming is that it only performs mechanized average processing on the index weighting results of each expert. The BBWM method proposed in this study introduces probability factors and takes into account the influence of experts' group decision-making on the results of index weighting, which can effectively overcome the disadvantage of the BWM method.

3.3.2. Applicability and Advantages of the Performance Evaluation Method. GRA is widely used in various fields for its low requirements on the research object: (1) it is not limited to the sample size, and (2) it does not require the regularity of the sample. But, the disadvantage of GRA is ignoring the degree of numerical proximity for indicators. By simultaneously considering the degree of geometric similarity and the degree of numerical proximity, DQ-GRA proposed in this study can effectively solve the problems of traditional GRA.

3.4. The Framework of the Proposed Model. The framework of the proposed model is shown in Figure 3 as follows.

\section{Case Study}

4.1. Basic Information of the Cases. In this section, 5G base stations in a certain area are selected for comprehensive performance evaluation. The distribution map (simplified version) of base stations and population in this area is shown in Figure 4. The main parameters of each base station are shown in Table 4.

4.2. Determination of the Weights of Performance Evaluation Indicators. As mentioned above, the BBWM is employed to determine the weights of the six indicators and five experts should propose their suggestions and preferences. According to the steps of BBWM, experts should determine the best indicator and the worst indicator of the proposed performance evaluation index system first, which are, respectively, listed in Table 5. 


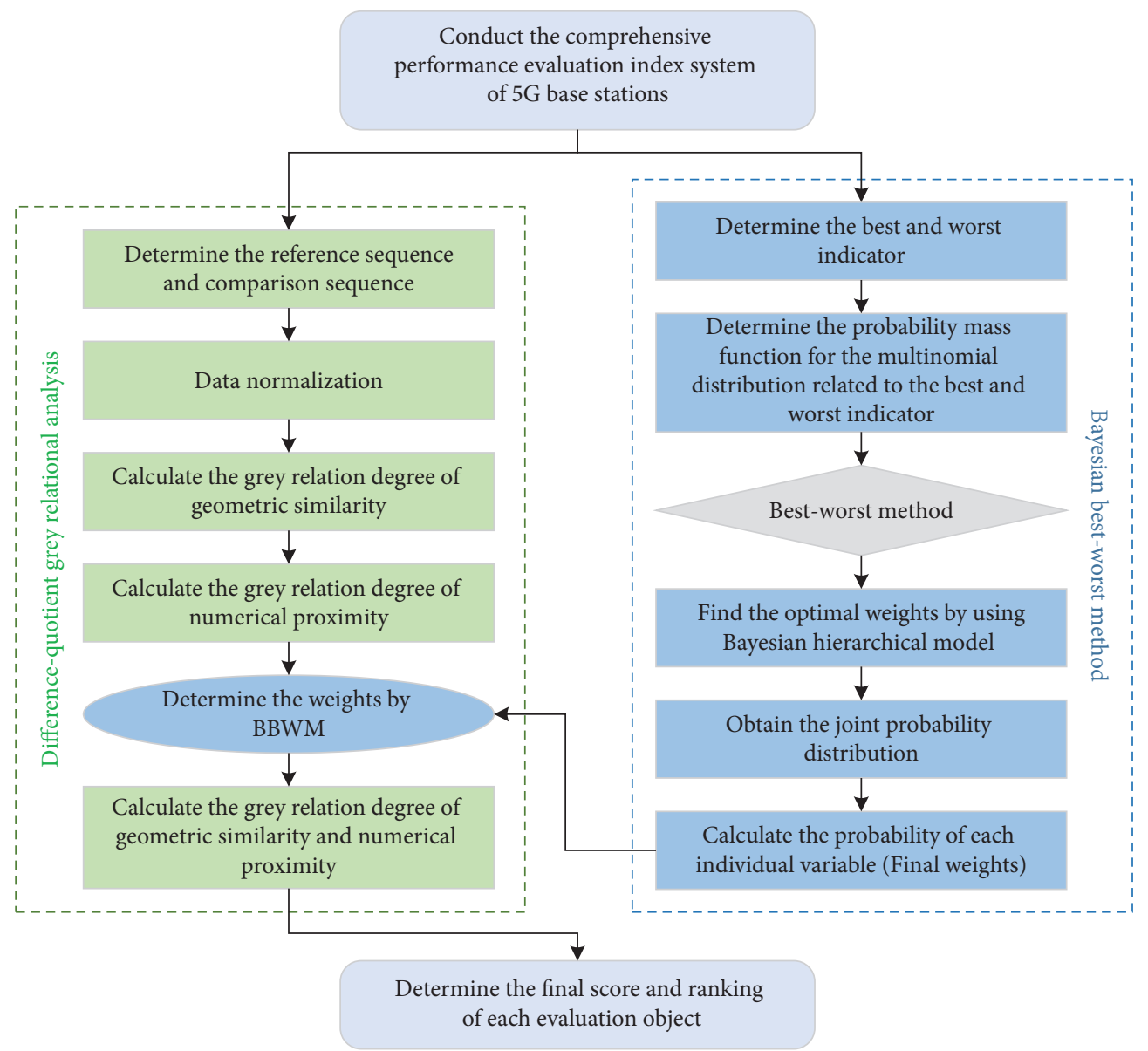

Figure 3: The framework of the proposed model.

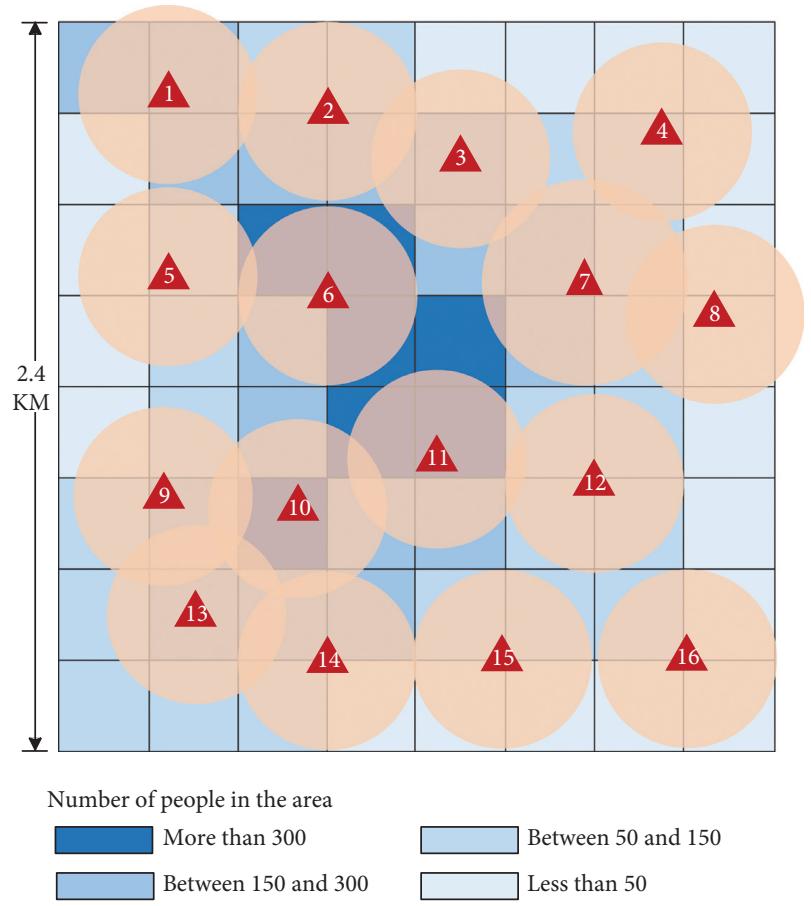

FIgURE 4: The distribution map of base stations and population in the area.
After selecting the best and worst indicators, pairwise comparisons between the best indicator and other indicators should be given by the five experts. The pairwise comparisons are shown in Table 6.

Similarly, the pairwise comparisons between the worst indicator and other indicators should also be given by the five experts. The pairwise comparisons are shown in Table 7.

Then, the "Best-to-Others" pairwise comparison vector $A_{B}^{1: K}$ and the "Others-to-Worst" pairwise comparison vector $A_{W}^{1: K}$ can be obtained as follows:

$$
A_{B}^{1: 5}=\left(\begin{array}{cccccc}
1 & 4 & 2 & 6 & 3 & 5 \\
1 & 4 & 3 & 5 & 2 & 6 \\
1 & 6 & 2 & 3 & 4 & 5 \\
1 & 5 & 2 & 6 & 3 & 4 \\
1 & 4 & 3 & 6 & 2 & 5
\end{array}\right), A_{W}^{1: 5}=\left(\begin{array}{cccccc}
6 & 3 & 5 & 1 & 4 & 2 \\
6 & 3 & 4 & 2 & 5 & 1 \\
6 & 1 & 5 & 4 & 3 & 2 \\
6 & 2 & 5 & 1 & 4 & 3 \\
6 & 3 & 4 & 1 & 5 & 2
\end{array}\right) .
$$

$K=5$ represents five experts who participated in the decision-making.

The overall optimal weight $w^{\text {agg }}$ can be calculated by the weight of each decision-maker $w^{k}$, which is computed by $A_{B}^{1: K}$ and $A_{W}^{1: K}$, and the process is calculated through MATLAB software. The values of ten indicator weights are listed in Table 8. 
TABLE 4: The main parameters of each base station.

\begin{tabular}{|c|c|c|c|c|c|c|}
\hline $\begin{array}{l}5 \mathrm{G} \text { base } \\
\text { station }\end{array}$ & $\begin{array}{l}\text { Signal coverage } \\
\text { area }\left(10^{4} \mathrm{~m}^{2}\right)\end{array}$ & $\begin{array}{c}\text { Annual average } \\
\text { business loadings } \\
(\mathrm{kW})\end{array}$ & $\begin{array}{c}\text { Per capita input } \\
\text { cost (yuan/ } \\
\text { person) }\end{array}$ & $\begin{array}{c}\text { Electric field } \\
\text { intensity }(\mathrm{V} / \mathrm{m})\end{array}$ & $\begin{array}{c}\text { Number of dangerous } \\
\text { factories and nearby } \\
\text { enterprises }\end{array}$ & $\begin{array}{c}\text { User experience } \\
\text { degree }\end{array}$ \\
\hline BS1 & 27.43 & 17.1 & 320.10 & 2.68 & 0 & 5.7 \\
\hline BS2 & 26.23 & 14.2 & 385.47 & 3.88 & 0 & 6.8 \\
\hline BS3 & 26.55 & 13.6 & 402.48 & 4.12 & 0 & 7.1 \\
\hline BS4 & 27.96 & 7.2 & 760.23 & 6.11 & 4 & 8.7 \\
\hline BS5 & 27.96 & 8.5 & 643.96 & 5.36 & 1 & 8.3 \\
\hline BS6 & 27.96 & 26 & 210.53 & 0.97 & 0 & 4.2 \\
\hline BS7 & 24.28 & 14 & 390.98 & 4.09 & 0 & 6.8 \\
\hline BS8 & 21.99 & 4 & 1368.42 & 6.78 & 2 & 9.3 \\
\hline BS9 & 21.87 & 8.9 & 615.02 & 5.62 & 1 & 8.1 \\
\hline BS10 & 22.56 & 14.7 & 372.36 & 3.65 & 0 & 6.5 \\
\hline BS11 & 26.70 & 22 & 248.80 & 1.32 & 0 & 5.1 \\
\hline BS12 & 27.96 & 12 & 456.14 & 5.11 & 0 & 7.6 \\
\hline BS13 & 21.74 & 13.6 & 402.48 & 4.57 & 0 & 7.3 \\
\hline BS14 & 26.14 & 13.1 & 417.84 & 4.66 & 0 & 7.4 \\
\hline BS15 & 28.27 & 8 & 684.21 & 5.87 & 4 & 8.5 \\
\hline BS16 & 28.27 & 6 & 912.28 & 6.36 & 4 & 9.1 \\
\hline
\end{tabular}

Note: the range of the value for the user experience degree indicator is (0-10), ten means best, and zero means worst.

TABLe 5: The best and worst indicators are determined by five invited experts.

\begin{tabular}{lcc}
\hline Expert number & The best indicator & The worst indicator \\
\hline 1 & $\mathrm{C} 1$ & $\mathrm{C} 4$ \\
2 & $\mathrm{C} 1$ & $\mathrm{C} 6$ \\
3 & $\mathrm{C} 1$ & $\mathrm{C} 2$ \\
4 & $\mathrm{C} 1$ & $\mathrm{C} 4$ \\
5 & $\mathrm{C} 1$ & $\mathrm{C} 4$ \\
\hline
\end{tabular}

TABle 6: Pairwise comparisons between the best indicator and other indicators.

\begin{tabular}{lccccc}
\hline Expert number & 1 & 2 & 3 & 4 & 5 \\
\hline The best indicator & $\mathrm{C} 1$ & $\mathrm{C} 1$ & $\mathrm{C} 1$ & $\mathrm{C} 1$ & $\mathrm{C} 1$ \\
C1 & 1 & 1 & 1 & 1 & 1 \\
C2 & 4 & 4 & 6 & 5 & 4 \\
C3 & 2 & 3 & 2 & 2 & 3 \\
C4 & 6 & 5 & 3 & 6 & 6 \\
C5 & 3 & 2 & 4 & 3 & 2 \\
C6 & 5 & 6 & 5 & 4 & 5 \\
\hline
\end{tabular}

TABle 7: Pairwise comparisons between the worst indicator and other indicators.

\begin{tabular}{lccccc}
\hline Expert number & 1 & 2 & 3 & 4 & 5 \\
\hline The worst indicator & $\mathrm{C} 4$ & $\mathrm{C} 6$ & $\mathrm{C} 2$ & $\mathrm{C} 4$ & $\mathrm{C} 4$ \\
C1 & 6 & 6 & 6 & 6 & 6 \\
C2 & 3 & 3 & 1 & 2 & 3 \\
C3 & 5 & 4 & 5 & 5 & 4 \\
C4 & 1 & 2 & 4 & 1 & 1 \\
C5 & 4 & 5 & 3 & 4 & 5 \\
C6 & 2 & 1 & 2 & 3 & 2 \\
\hline
\end{tabular}

It can be seen that the value of signal coverage area $(\mathrm{C} 1)$ is highest, followed by per capita input cost (C3), safety impact (C5), business loadings (C2), and user experience degree (C6), and ecological environmental impact (C4) is lowest.
TABLE 8: Weights of ten indicators.

\begin{tabular}{lcccccc}
\hline Indicator & C1 & C2 & C3 & C4 & C5 & C6 \\
\hline Value of weights & 0.3071 & 0.1385 & 0.2118 & 0.0890 & 0.1557 & 0.0979 \\
\hline
\end{tabular}

The credal ranking is shown in Figure 5, which can reflect the confidence level of the relationship between six indicators. The closer the result is to 1 , the higher the level of credal ranking is, which means that the experts have more consistent views on the relationship between multiple indicators.

From Figure 5, the credal ranking of six indicators for performance evaluation of $5 \mathrm{G}$ base stations can be clearly obtained. The value of "signal coverage area indicator (C1)" is taken as an example, it is obviously more important than $\mathrm{C} 2, \mathrm{C} 4$, and $\mathrm{C} 6$ with the credal ranking of 1 , and it is also important than C5 with the confidence of 0.99 and C3 with the confidence of 0.93 .

4.3. Results of the Performance Evaluation for $5 G$ Base Stations. Based on the basic information of each $5 \mathrm{G}$ base station, the DQ-GRA model is adopted in this section to evaluate the comprehensive performance of 16 base stations. The evaluation results are presented in Figure 6 and the descriptive statistics of the evaluation results are listed in Table 9.

According to the results of the performance evaluation for sixteen $5 \mathrm{G}$ base stations, several conclusions can be obtained:

(1) BS6 performs best of the sixteen $5 \mathrm{G}$ base stations with the gray relation degree of 0.955 . This result may be due to the following reasons: (1) the location of BS6 is in a densely populated central area. Although the user experience around the base station is not so good, it greatly reduces the per capita investment cost. (2) The base station does not overlap with other base stations, so it can guarantee the full coverage of 


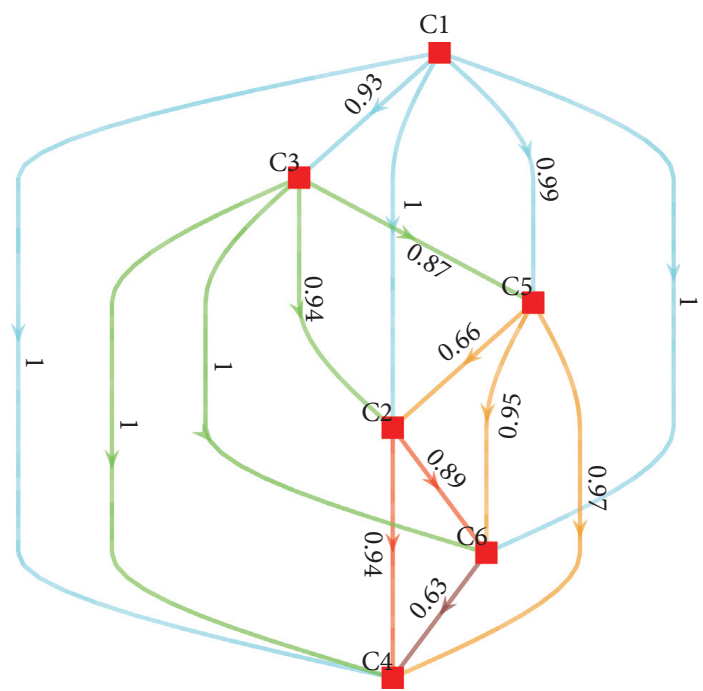

Figure 5: The credal ranking of six indicators for performance evaluation of $5 \mathrm{G}$ base stations.

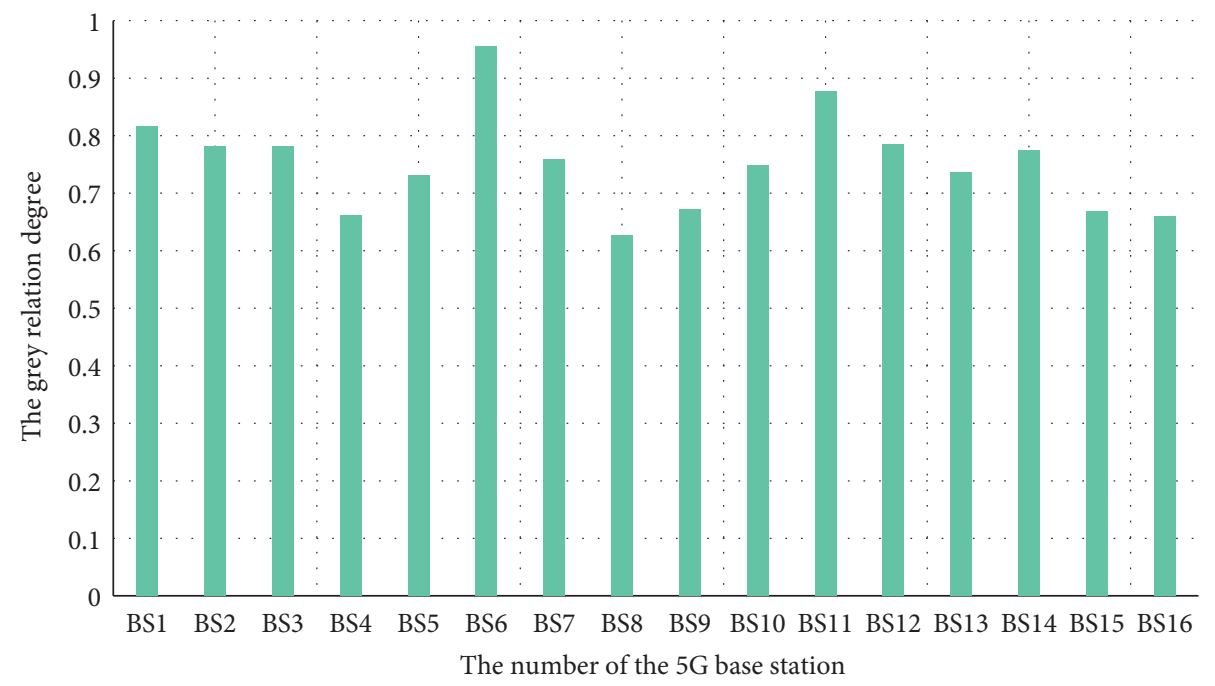

Figure 6: Results of the performance evaluation for 5G base stations.

TABLE 9: The descriptive statistics of the evaluation results.

\begin{tabular}{lcc}
\hline Dimension & Value & 5G base station \\
\hline Max & 0.955 & BS6 \\
Min & 0.626 & BS8 \\
Average & 0.752 & - \\
\hline
\end{tabular}

the signal. (3) The ecological environmental impact of BS6 is relatively small, and no dangerous factories or enterprises are built around.

(2) BS8 performs worst of the sixteen 5G base stations with the gray relation degree of 0.626 . This result may be due to the following reasons: (1) the location of BS8 is in a surrounding area with fewer people, which leads to the high cost of $5 \mathrm{G}$ base station investment. (2) The ecological environmental impact of BS8 is huge, and several dangerous factories or enterprises are built around.
(3) Overall, the comprehensive performance of the sixteen $5 \mathrm{G}$ base stations evaluated in this study is not satisfactory, and the average value of gray relation degree for sixteen $5 \mathrm{G}$ base stations is only 0.752 . The number of $5 \mathrm{G}$ base stations whose evaluation performance is higher than the average and below the average is the same.

\section{Comparison of the Results}

In order to prove the superiority and advancement of the model proposed in this study, several comparative models are proposed in this section (listed in Table 10).

5.1. Comparison of the Results by Model 1 and Model 2. According to the expert decision results listed from Table 5 to Table 7, the indicator weights determined by five experts 
TABLE 10: The models for ranking similarity comparison.

\begin{tabular}{lc}
\hline Models & Model description \\
\hline Model 1 & The proposed hybrid MCDM model based on BBWM and DQGRA \\
Model 2 & The hybrid MCDM model based on BWM and DQGRA \\
Model 3 & The hybrid MCDM model based on BBWM and GRA \\
\hline
\end{tabular}

TABLE 11: The indicator weights are determined by five experts based on the traditional BWM.

\begin{tabular}{|c|c|c|c|c|c|c|}
\hline Indicator & $\mathrm{C} 1$ & $\mathrm{C} 2$ & $\mathrm{C} 3$ & $\mathrm{C} 4$ & C5 & C6 \\
\hline Value of weights (expert 1 ) & 0.3312 & 0.1047 & 0.2828 & 0.0484 & 0.15320 & 0.0796 \\
\hline Value of weights (expert 2) & 0.3390 & 0.1072 & 0.1568 & 0.0581 & 0.2894 & 0.0496 \\
\hline Value of weights (expert 3 ) & 0.3312 & 0.0484 & 0.2828 & 0.1532 & 0.1047 & 0.0795 \\
\hline Value of weights (expert 4 ) & 0.3605 & 0.0866 & 0.2194 & 0.0527 & 0.1667 & 0.1140 \\
\hline Value of weights (expert 5) & 0.3778 & 0.1398 & 0.0939 & 0.0518 & 0.2461 & 0.0906 \\
\hline Value of weights (final) & 0.34794 & 0.09734 & 0.20714 & 0.07284 & 0.19202 & 0.08266 \\
\hline
\end{tabular}

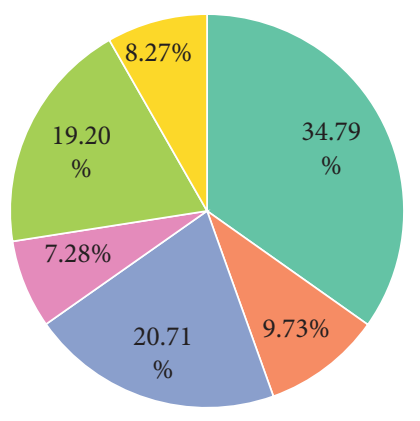

$$
\begin{array}{ll}
-\mathrm{C} 1 & -\mathrm{C} 4 \\
-\mathrm{C} 2 & =\mathrm{C} 5 \\
-\mathrm{C} 3 & =\mathrm{C} 6
\end{array}
$$

(a)

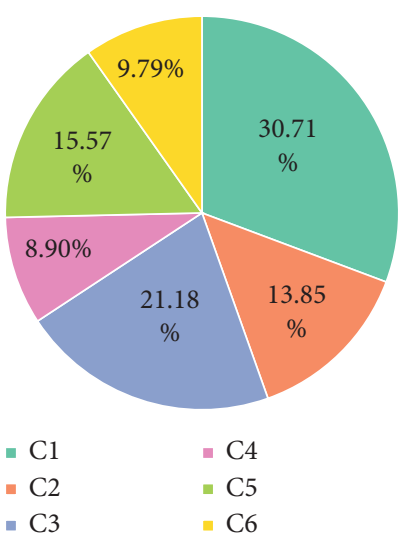

(b)

FIgURE 7: The indicator weights calculated by BWM and BBWM. (a) Indicator weights by BWM. (b) Indicator weights by BBWM.

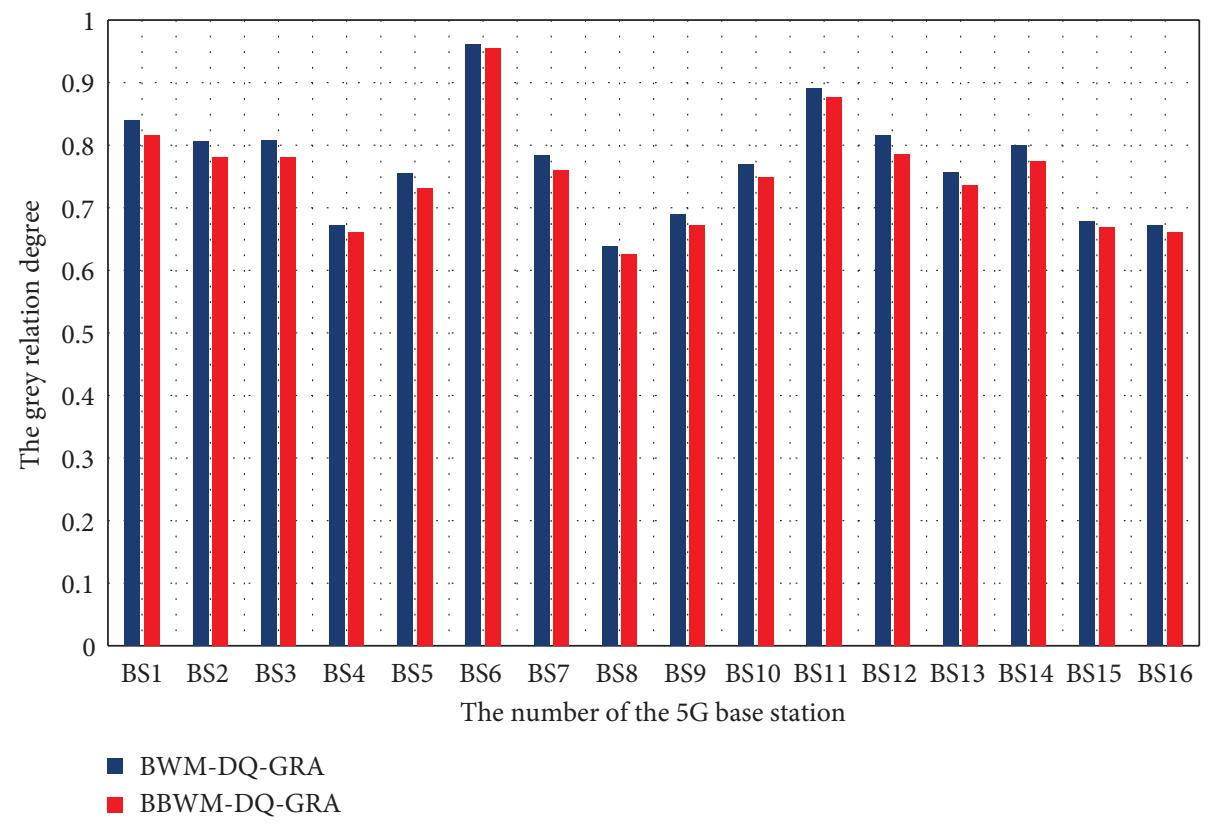

FIGURE 8: Results of the performance evaluation for 5G base stations based on BWM-DQ-GRA and BBWM-DQ-GRA. 


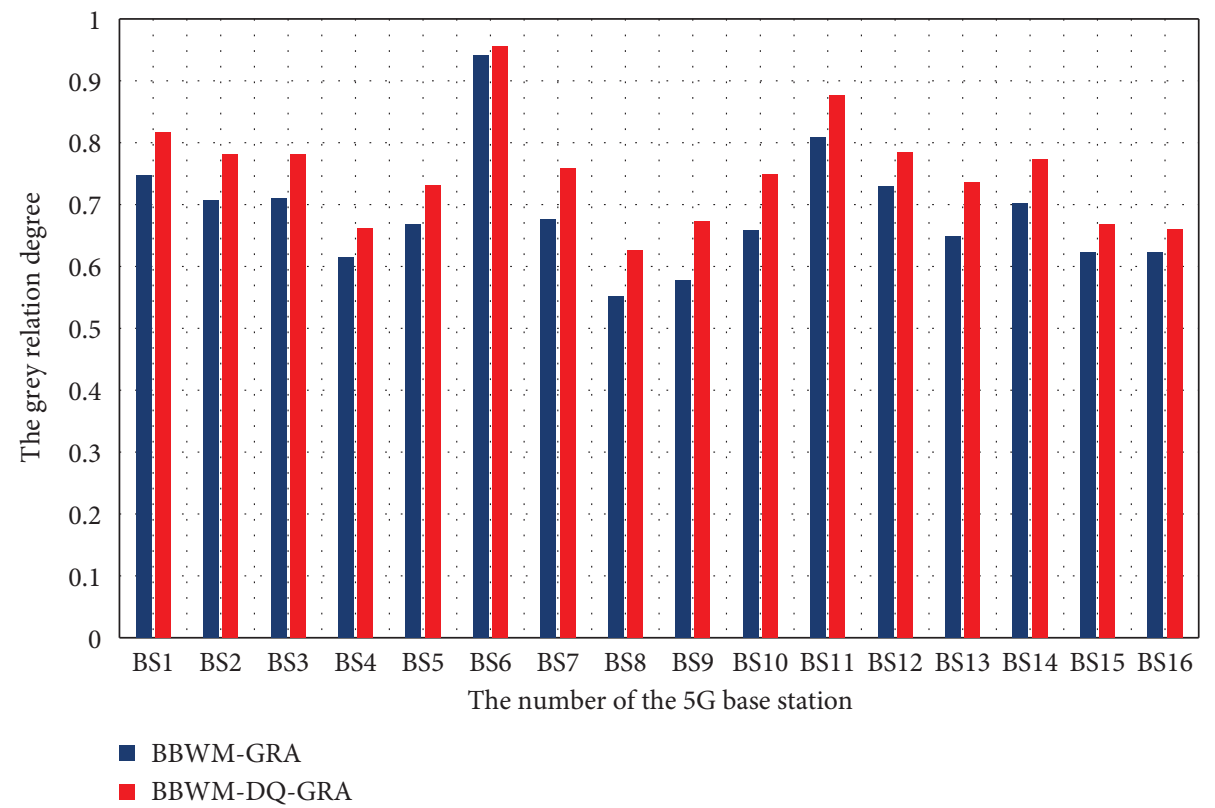

FIGURE 9: Results of the performance evaluation for 5G base stations based on BBWM-GRA and BBWM-DQ-GRA.

based on the traditional BWM are listed in Table 11. The indicator weights calculated by BWM and BBWM are shown in Figure 7.

As can be seen from Table 11 and Figure 7, although the weight of each indicator has changed, the importance ranking of each indicator has not changed. On the one hand, the result proves the rationality of BBWM, that is, the ranking of importance for the indicators has not changed due to method improvements. On the other hand, a certain decision-making environment is formed by introducing Bayesian theory into the traditional BWM, which can avoid further expansion of the difference between indicators.

Figure 8 shows the results of the performance evaluation for $5 \mathrm{G}$ base stations based on BWM-DQ-GRA and BBWMDQ-GRA.

By using BBWM-DQ-GRA, the weight distribution among indicators is more reasonable. Hence, the comprehensive performance of each $5 \mathrm{G}$ base station has decreased, which can better reflect the actual performance of the base station.

5.2. Comparison of the Results by Model 1 and Model 3. Figure 9 shows the results of the performance evaluation for $5 \mathrm{G}$ base stations based on BBWM-GRA and BBWM-DQGRA.

According to Figure 9, the comprehensive performance of each $5 \mathrm{G}$ base station has increased by using BBWM-DQGRA, which can better reflect the actual performance of the base station.

\section{Conclusions and Limitations}

With the continuous development of 5G technology, more and more $5 \mathrm{G}$ base stations are being constructed to meet people's daily needs. Therefore, the performance evaluation can not only measure whether the base station has met the expected requirements but also provide a reference for subsequent $5 \mathrm{G}$ base station site selection planning. This study presents a novel hybrid MCDM model to evaluate the comprehensive performance of $5 \mathrm{G}$ base stations, which is composed of BBWM and DQ-GRA. Several conclusions can be drawn as follows:

(1) According to the weight determination results, experts agree that the signal coverage area and per capita input cost are key indicators for evaluating the comprehensive benefits of $5 \mathrm{G}$ base stations. In contrast, indicators such as the ecological environmental impact and user experience are less important.

(2) According to the evaluation results, the performance of each base station is quite different. The average value of the comprehensive performance of each base station is only 0.752 , which is not satisfactory and needs to be improved in the construction of $5 \mathrm{G}$ base stations in the future.

(3) Through the improvement of the index weighting method and evaluation method, the comprehensive performance of each base station is finally obtained to be more reasonable and authentic. The BBWM method and DQ-GRA method can be further applied in other fields.

Moreover, some limitations and future directions are summarized as follows:

(1) From the perspective of methodology. Although the proposed method in this study solves the problems of the original method to some extent, it indeed increases the complexity of the method, which leads to an increase in the computational process and time. 
In the future, more efficient and convenient methods are needed in addition to the improvement of the existing defects.

(2) From the perspective of subject. Due to the availability of data, the capacity of the simulation sample is limited, which may affect the final evaluation results to some extent. The scope of the study population needs to be further expanded in future work, and the impact on 5G base station site planning needs to be further analyzed on the basis of the performance evaluation.

\section{Data Availability}

The $5 \mathrm{G}$ base station data used to support the findings of this study are included within the article.

\section{Conflicts of Interest}

The authors declare that there are no conflicts of interest regarding the publication of this paper.

\section{Acknowledgments}

This research was funded by the National Natural Science Foundation of China, grant no. 71973043.

\section{References}

[1] A. Gohil, H. Modi, and S. K. Patel, "5G technology of mobile communication: a survey," in Proceedings of the 2013 International Conference on Intelligent Systems and Signal Processing (ISSP), pp. 288-292, Vallabh Vidyanagar, India, March 2013.

[2] J. Sun, Q. Yu, M. Niyazbek, and F. Chu, "WITHDRAWN: 5G network information technology and military information communication data services," Microprocessors and Microsystems, 2020, In press, Article ID 103459.

[3] Y. Jiang, W. Jiang, and H. Yang, "Application and research on 5G wireless network deployment," Telecommunications Information, vol. 5, no. 2, pp. 11-14, 2018.

[4] I. F. Akyildiz, S. Nie, S.-C. Lin, and M. Chandrasekaran, "5G roadmap: 10 key enabling technologies," Computer Networks, vol. 106, pp. 17-48, 2016.

[5] R. Charles, A. Almasarani, and M. A. Majid, "5G-Wireless sensor networks for smart grid-accelerating technology's progress and innovation in the kingdom of Saudi arabia," Procedia Computer Science, vol. 182, no. 4, pp. 46-55, 2021.

[6] Y. Xie, S. Wang, B. Wang, S. Xu, X. Wang, and J. Ren, "Online algorithm for migration aware Virtualized Network Function placing and routing in dynamic 5G networks," Computer Networks, vol. 194, no. 99, Article ID 108115, 2021.

[7] S. Juneja and R. Sharma, "Semiconductor technologies for 5G implementation at millimeter wave frequencies - design challenges and current state of work," Engineering Science and Technology an International Journal, vol. 24, pp. 205-217, 2020.

[8] F. Wen, H. Wymeersch, B. Peng, W. P. Tay, H. C. So, and D. Yang, "A survey on 5G massive MIMO localization," Digital Signal Processing, vol. 94, pp. 21-28, 2019.

[9] N. Sharma and K. Kumar, "Resource allocation trends for ultra dense networks in $5 \mathrm{G}$ and beyond networks: a classification and comprehensive survey," Physical Communication, vol. 48, no. 4, Article ID 101415, 2021.

[10] K. Liu, Y. Liu, J. Liu, and A. Argyriou, "Tile caching for scalable VR video streaming over 5G mobile networks," Journal of Visual Communication and Image Representation, vol. 79, Article ID 103210, 2021.

[11] Y. Wang, W. Ning, S. Zhang, H. Yu, H. Cen, and S. Wang, "Architecture and key terminal technologies of 5G-based internet of vehicles," Computers \& Electrical Engineering, vol. 95, Article ID 107430, 2021.

[12] L. Yang, Z. Li, S. Ma, and X. Yang, “Artificial intelligence image recognition based on $5 \mathrm{G}$ deep learning edge algorithm of Digestive endoscopy on medical construction," Alexandria Engineering Journal, vol. 61, no. 3, pp. 1852-1863, 2021.

[13] Y. Jararweh, "Enabling efficient and secure energy cloud using edge computing and 5G," Journal of Parallel and Distributed Computing, vol. 145, pp. 42-49, 2020.

[14] L. Tan, H. Xiao, K. Yu, M. Aloqaily, and Y. Jararweh, "A blockchain-empowered crowdsourcing system for 5G-enabled smart cities," Computer Standards \& Interfaces, vol. 76, Article ID 103517, 2021.

[15] X. Yan and M. Ma, "A lightweight and secure handover authentication scheme for $5 \mathrm{G}$ network using neighbour base stations," Journal of Network and Computer Applications, vol. 193, Article ID 103204, 2021.

[16] Q. Wang, X. Zhao, Z. Lv, X. Ma, R. Zhang, and Y. Lin, "Optimizing the ultra-dense $5 \mathrm{G}$ base stations in urban outdoor areas: coupling GIS and heuristic optimization," Sustainable Cities and Society, vol. 63, Article ID 102445, 2020.

[17] T. Sigwele, Y. F. Hu, and M. Susanto, "Energy-efficient 5G cloud RAN with virtual BBU server consolidation and base station sleeping," Computer Networks, vol. 177, Article ID 107302, 2020.

[18] M. Qian, Y. Wang, Y. Zhou, L. Tian, and J. Shi, "A super base station based centralized network architecture for $5 \mathrm{G}$ mobile communication systems," Digital Communications and Networks, vol. 1, no. 2, pp. 152-159, 2015.

[19] Z. Chen, Y. Fan, and P. Jia, "Influence of buried depth on seismic capacity of underground subway stations through performance-based evaluation," Structures, vol. 32, no. 3, pp. 194-203, 2021.

[20] M. R. Galankashi, E. Fallahiarezoudar, A. Moazzami, N. M. Yusof, and S. A. Helmi, "Performance evaluation of a petrol station queuing system: a simulation-based design of experiments study," Advances in Engineering Software, vol. 92, pp. 15-26, 2016.

[21] R. Dabou, A. Bouraiou, A. Ziane et al., "Development of autonomous monitoring and performance evaluation system of grid-tied photovoltaic station," International Journal of Hydrogen Energy, vol. 46, no. 59, pp. 30267-30287, 2021.

[22] M. Ciciolu, "Performance analysis of handover management in 5G small cells," Computer Standards \& Interfaces, vol. 75, Article ID 103502, 2021.

[23] D. Sun, "Radiated Spurious Emission test system based on mobile user terminal," Electronic Product Reliability and Environmental Testing, vol. 38, no. 6, pp. 12-14, 2020.

[24] M. Sun, X. Zhao, H. Tan, and X. Li, "Coordinated operation of the integrated electricity-water distribution system and watercooled 5G base stations," Energy, vol. 238, Article ID 122034, 2021.

[25] J. Rezaei, "Best-worst multi-criteria decision-making method," Omega, vol. 53, pp. 49-57, 2015.

[26] A. Karam, M. Hussein, and K. H. Reinau, "Analysis of the barriers to implementing horizontal collaborative transport 
using a hybrid fuzzy Delphi-AHP approach," Journal of Cleaner Production, vol. 321, Article ID 128943, 2021.

[27] M. Mohammadi and J. Rezaei, "Bayesian best-worst method: a probabilistic group decision making model," Omega, vol. 96, Article ID 102075, 2019.

[28] N. Li and H. Zhao, "Performance evaluation of eco-industrial thermal power plants by using fuzzy GRA-VIKOR and combination weighting techniques," Journal of Cleaner Production, vol. 135, pp. 169-183, 2016.

[29] Y. Wu, J. Lei, L. Bao, and C. Li, "Short-term load forecasting based on improved grey relational analysis and neural network optimized by bat algorithm," Automation of Electric Power Systems, vol. 42, no. 20, pp. 67-74, 2018.

[30] W. Xue, B. Li, Y. Yang, H. Zhao, and N. Xu, "Evaluating the effectiveness of new and old kinetic energy conversion from an electric power economics perspective: evidence on the shandong province of China," Energies, vol. 12, no. 6, Article ID 1174, 2019.

[31] T. Wang, Z. A. Du, K. Zhang, K. Chen, F. Xiao, and P. Ye, "Reliability evaluation of high voltage direct current transmission protection system based on interval analytic hierarchy process and interval entropy method mixed weighting," Energy Reports, vol. 7, no. 16, pp. 90-99, 2021.

[32] T.-H. Wu, Y.-F. Chung, and S.-W. Huang, "Evaluating global energy security performances using an integrated PCA/DEAAR technique," Sustainable Energy Technologies and Assessments, vol. 45, no. 5, Article ID 101041, 2021.

[33] L. Wang, Y. Li, Y. Wang et al., "Compensation benefits allocation and stability evaluation of cascade hydropower stations based on Variation Coefficient-Shapley Value Method," Journal of Hydrology, vol. 599, Article ID 126277, 2021. 